\title{
Instituciones públicas e instrumentos privados de protección: una perspectiva de conjunto
}

\section{Manuela Durán Bernardino}

Acreditada al cuerpo de profesor contratado doctor de universidad

Departamento de Derecho del Trabajo y de la Seguridad Social

Universidad de Granada

<mduranb@ugr.es>

\begin{abstract}
Azterlan honen xedea da mendetasun egoeran dauden pertsona eta berauen zaintzaileen premiei aurre egitean Gizarte Segurantza, gizarte-zerbitzu eta Osasun Sistema Nazionalak eskaini izandako estaldura aztertzea. Horretaz gain, antzeman nahi dira instituzio bakoitzak egungo aldaketa soziodemografiko eta ekonomikoen aurrean agerian dituzten gabeziak; gaur egun, mendeko diren pertsonen babesean betetzen dituzten rolak aztertzea; eta azkenik, proposamen batzuek bideratzen dira babes sozialeko sistemaren eraginkortasun eta efizientzia globala sustatzeko. Horretaz gain, noski, oso kontuan hartzen da kolektibo horren babesean familietako zaintzaileen ezinbestekoa tradizionala izan den rol hori, eta baita ere azken urteotan baliabide pribatuek hartutako dimentsio garrantzitsua.
\end{abstract}

\section{GAKO-HITZAK:}

Autonomia pertsonala, mendetasuna, epe luzeko zainketak, babes publikoa, babes pribatua.
El objeto del presente artículo es examinar la cobertura que la Seguridad Social, los servicios sociales y el Sistema Nacional de Salud han dado al conjunto de necesidades a las que se enfrentan los dependientes y sus cuidadores; detectar las carencias que presentan cada uno de ellos en este ámbito, ante los cambios sociodemográficos y económicos actuales; analizar el papel que siguen desempeñando en la protección de las personas dependientes en la actualidad; para finalmente enunciar algunas propuestas de mejora dirigidas, en todo caso, a fomentar la eficacia y eficiencia del sistema global de protección social. Todo ello, sin olvidar el papel fundamental y tradicional que han ejercido los cuidadores familiares en la protección de este colectivo, así como la importante dimensión que están adquiriendo los instrumentos privados en los últimos años.

\section{Palabras Clave:}

Autonomía personal, dependencia, cuidados de larga duración, protección pública, protección privada. 


\section{La atención a la dependencia en el sistema español de la Seguridad Social}

Dentro de la acción protectora del sistema de Seguridad Social se contemplan algunas prestaciones que responden a la atención de algunas necesidades de las personas dependientes o compensan económicamente al cuidador, aunque como veremos, lo hace de forma inadecuada, debido principalmente a antecedentes históricos en los que la protección social siempre ha estado en conexión con las contingencias profesionales (Aznar López, 2001: 50), dando prioridad a la cobertura de dichos riesgos.

Esta tendencia histórica explica que los antecedentes de la atención a las personas en situación de la dependencia se enmarquen en la protección por contingencias profesionales, por lo que originariamente no se atendía a cualquier situación de dependencia, sino sólo a aquella que enlazara con los requisitos de profesionalidad (ya que el sujeto que la sufriera debía ser un trabajador) y tuviera su causa directa en el trabajo realizado, siendo estas las bases de la gran invalidez y por extensión de la dependencia.

Esto fue así hasta la aprobación de la Ley 13/1982, de 7 de abril, de Integración Social de los Minusválidos, en la que se incluyó un subsidio por ayuda de tercera persona, eliminándose el requisito de ser "trabajador”, y sin fijar ningún límite máximo de edad (arts. 12 y 16), siendo lo esencial la necesidad de los cuidados de otra persona para realizar los actos más elementales de la vida, y no la mayor pérdida de capacidad laboral. Nos encontramos ante el antecedente directo del actual complemento de la pensión de invalidez en su nivel no contributivo (Aznar López, 2001: 52). Sin embargo, la Ley $26 / 1990$, de 20 de diciembre, por la que se establecen en la Seguridad Social Prestaciones no contributivas, derogó este régimen estableciendo un límite máximo de 65 años, al entender que, una vez cumplida dicha edad, el acceso a las pensiones ha de realizarse por la vía de la jubilación.

En consecuencia, por un lado quedan desprotegidos los mayores de 65 , que constituyen el colectivo que más ayuda necesita por el aumento de enfermedades asociadas a la edad, y por otro, aquellos sujetos que no tengan la condición de trabajador, caracterizados por unos ingresos insuficientes para afrontar los enormes gastos de la atención que precisen. Ello muestra la inadaptación e insuficiencia de las prestaciones económicas del sistema para atender las necesidades que presentan las personas dependientes, máxime en el contexto actual, caracterizado por la generalización de dicho riesgo. Lo deseable habría sido la articulación de un sistema protector diferenciado para tales situaciones (Monereo Pérez et al., 2010: 236).

Actualmente, nuestro sistema de Seguridad Social, regulado por el Real Decreto Legislativo 1/1994, de 20 de junio, contempla diferentes prestaciones con las que, de forma relativamente directa, se ha venido dando cobertura económica a las situaciones de dependencia, previéndose en alguna de ellas complementos para compensar los cuidados en el caso de que alguna persona beneficiaria requiera la asistencia de otra para realizar los actos esenciales de la vida diaria (Molero Marañón, 2004). Así ocurre en las siguientes prestaciones:

a. Prestación por incapacidad permanente en el grado de gran invalidez.

b. Complemento del $50 \%$ previsto para la invalidez no contributiva.

c. Prestaciones económicas por hijo a cargo discapacitado.

d. Pensiones a favor de hijos o hermanos que acrediten una dedicación prolongada al cuidado del dependiente fallecido.

e. Incapacitados mayores de 18 años con el grado de gran invalidez cuyos padres (pensión de orfandad), abuelos o hermanos fallezcan (pensión a favor de familiares).

f. Prestación por jubilación.

g. Pensión de viudedad.

Sin embargo, la dependencia en nuestro país no es una contingencia específicamente protegida por la Seguridad Social, pues sólo de forma indirecta y fragmentada se tutelan determinados aspectos 0 dimensiones de aquélla a través de prestaciones que hoy día no cubren completamente las necesidades de los sujetos afectados y de sus familias (Sempere Navarro, 2008: 93), dejando sin protección a muchas personas dependientes. En particular, no siempre se dispensa una protección específica a quienes necesitan ayuda de tercera persona para realizar las actividades básicas de la vida diaria; la mayoría de las prestaciones están vinculadas a la actividad profesional (nivel contributivo), sin distinguir entre dependencia e incapacidad para el trabajo (González Ortega, 2004: 125); las prestaciones de corte contributivo exigen un periodo de cotización previo, lo que deja a muchas personas dependientes sin protección, mientras que en las prestaciones de carácter no contributivo la carencia de recursos es una conditio sine qua non, pues en ellas no tienen cabida aquellas personas dependientes que superan el umbral de pobreza, aspecto que no guarda relación alguna con las situaciones de dependencia; en ocasiones, existen limitaciones al acceso a la prestación relacionadas con la edad de las personas beneficiarias; y no se prevén prestaciones de servicios destinadas a la prevención y promoción de la autonomía y atención personal.

Dichas carencias podrían resolverse dentro del propio ámbito de la Seguridad Social, pero confiriéndole una configuración autónoma e independiente (Barcelón Cobedo y Quintero Lima, 2006: 25-28) ${ }^{1}$, con la que se solventarían las

${ }^{1}$ Para estos autores, la alternativa más conveniente sería diseñar una prestación universal, de nivel no contributivo, pero de carácter no asistencial, para evitar que el nivel de rentas del sujeto dependiente 
vicisitudes que presenta su incardinación a otras prestaciones del sistema de Seguridad Social cuya adaptación devendría igualmente infructuosa (Rodríguez Cabrero, 1999: 23) ${ }^{2}$. Ésta sería la vía que nos habría aproximado a países como Alemania, donde la protección de la dependencia se considera una contingencia con entidad propia dentro del marco del sistema de Seguridad Social (modelo continental), garantizándose así como derecho subjetivo (Rodríguez Cabrero, 2004: 125).

Sin embargo, a pesar de existir los fundamentos teórico-jurídicos necesarios para insertar la protección de las personas dependientes en el marco de protección global del sistema de Seguridad Social y de los candentes pronunciamientos de la doctrina científica y jurisprudencial a favor de dicha inclusión (Suárez Corujo, 2006: 72; Vida Soria y Gonzalo González, 2006-2007: 121; Monereo Pérez et al., 2007: 65; Pérez Yánez, 2007: 422; González de Patto, 2011: 25; González Ortega, 2013: 57), el legislador no ha optado finalmente por esta alternativa.

Esta desvinculación del sistema de Seguridad Social posiblemente haya venido motivada por las siguientes razones. En primer lugar, se pretende garantizar una igualdad básica en todo el Estado español de la protección de los dependientes, por lo que el legislador elije como título competencial el art. 149.1.1 de la Constitución. Una segunda razón para rechazar el engarce con la Seguridad Social sería el importante papel que han de jugar las comunidades autónomas en la articulación del sistema de protección a las personas dependientes (incluso en su financiación). Se quiere primar la atención personal sobre la prestación económica y, como se sabe, la mayoría de las prestaciones que deben contemplarse ya venían funcionando dentro de los sistemas de salud y de servicios sociales (Maldonado Molina, 2011: 75). De ahí que la organización y gestión de la atención a la dependencia se haya descentralizado en las comunidades autónomas, que son los entes gestores y prestadores de asistencia. Además, se necesita la cooperación y colaboración de las comunidades autónomas para implantar y gestionar el sistema, pues ellas han construido y son las titulares de la red de servicios sociales (Beltrán Aguirre, 2008: 5). Pero el objeto principal de esta opción es preservar la viabilidad financiera del sistema de pensiones, asegurando los recursos necesarios para su sostenimiento. El Gobierno, consciente del elevado coste que supone comprender un nivel de prestaciones costoso y de dudosa viabilidad, con el que se pretende dar cobertura a la totalidad de necesidades causadas por la dependencia, consideró que se trataba de un gasto

\footnotetext{
o beneficiario-cuidador sea determinante en el acceso a la prestación que finalmente reciba.

${ }^{2}$ Donde se pone de manifiesto cómo la readaptación de las prestaciones del sistema de Seguridad Social con el objeto de dar cobertura a las situaciones de dependencia sólo serviría para justificar un cierto gasto público en protección de las situaciones de dependencia, gasto que sería más efectivo si se recondujera a una estructura protectora actualizada.
}

inasumible en solitario por la Administración Central que gestiona las prestaciones de Seguridad Social.

Estos argumentos que parecen justificar la no incardinación de la protección por dependencia en el sistema de Seguridad Social carecen de propia lógica si se tiene en cuenta que, en primer lugar, si lo que se pretendía era garantizar un nivel básico en todo el territorio estatal, el precepto constitucional con mayor peso jurídico es, sin duda, el artículo 149.1.17 ${ }^{\underline{a}}$ de la Constitución (y no el reclamado art. 149.1.1, débil e impreciso), ya que, como se sabe, reserva al Estado la competencia para dictar una legislación básica homogeneizadora y racionalizadora del tratamiento de las materias propias de la Seguridad Social en todo el territorio nacional. En segundo lugar, si la pretensión era que las comunidades autónomas siguieran desempeñando un papel fundamental en la articulación de este sistema protector, perfectamente se habría respetado reclamando el artículo 149.1.1 $7^{\underline{a}}$ de la Constitución, en tanto que expresamente deja constancia de los espacios de actuación reguladora que deja libre a las comunidades autónomas, en cuanto a la legislación no básica; y en cuanto a su financiación, su inclusión en el nivel no contributivo de la Seguridad Social (asistencia social interna) habría permitido su financiación vía impuesto, en la línea del modelo financiero que finalmente se ha implantado.

En definitiva, el legislador ha creado un sistema, prioritaria y fundamentalmente de servicios sociales (Vida Soria et al., 238), paralelo y complementario al sistema de Seguridad Social. No obstante, cabe advertir que la reciente opción legislativa no cierra la posibilidad de que, en el futuro, algunas de las prestaciones puedan pasar a integrar el ámbito de protección proporcionado por el sistema de la Seguridad Social, como en muchas instancias se viene defendiendo. El Tribunal de Justicia de la Unión Europea ha vuelto a insistir en esta consideración con la Sentencia de 30 de junio de 2011, al entender el riesgo de dependencia como prestación de Seguridad Social a todos los efectos.

\section{La atención a la dependencia en el Sistema Nacional de Salud}

\section{El Sistema Nacional de Salud tiene una doble} corresponsabilidad ante las situaciones de dependencia. En primer lugar, por la incidencia que han tenido los avances sanitarios en los altos índices de esperanza de vida alcanzados (Pérez Ortiz, 2012: 146-147) ${ }^{3}$, y en segundo, por las repercusiones que ocasiona el envejecimiento de la población en los recursos sanitarios necesarios para su atención.

\footnotetext{
${ }^{3}$ Aproximadamente a partir de 1970 , se empieza a percibir la incidencia de la sanidad en la mejora del estado de salud de los españoles, siendo la esperanza de vida al nacer de 72,4 años, y llegando a ser en la actualidad de 82,17 años. Estos resultados sitúan a España en uno de los países más longevos aún sin ser de los que más invierten en cuidados de la salud, lo que da muestra de la calidad de nuestro sistema sanitario.
} 
El desarrollo en la asistencia sanitaria pública y su universalización al conjunto de la población ha proporcionado amplios efectos beneficiosos, entre ellos, una notable prolongación de la vida del conjunto de la población y, en consecuencia, el aumento del número de personas que sufre alguna alteración física, psíquica o sensorial, a consecuencia de la edad, y necesitan inexorablemente de cuidados sanitarios y sociales (Cruz Villalón, 2007: 11).

Del mismo modo, enfermedades y accidentes que con anterioridad eran mortales, en la actualidad no lo son, gracias a los avances sanitarios; sin embargo, en numerosas ocasiones provocan secuelas profundan e irreversibles que repercuten directamente en la autonomía personal, haciendo necesaria la atención por parte de los servicios sanitarios durante el resto de su vida.

El objetivo de los sistemas sociales y sanitarios no termina con el incremento de los años de vida, sino que tiene por finalidad que esos años se vivan con la mayor capacidad funcional y con la mejor autonomía personal posible (Imserso, 2011: 233).

Como se comprueba, las situaciones de dependencia siempre han estado fuertemente vinculadas con el Sistema Nacional de Salud, pues un estado de dependencia - derivada del envejecimiento, de una enfermedad o de otras limitaciones- lleva aparejado la necesidad de ser atendidos por recursos sanitarios, bien de forma puntual o bien mediante asistencia de larga duración (como es en el caso de las enfermedades crónicas), en virtud del derecho de todos los ciudadanos a la protección de la salud, consagrado en el artículo 43 de nuestra Constitución ${ }^{4}$. Concretamente, esta relación viene justificada por los siguientes motivos (Imserso, 2011: 469; Sociedad Española de Geriatría y Gerontología, 2005: 4): por regla general, la causa principal de la dependencia son las enfermedades sufridas por la población y especialmente por las personas mayores, cuyo incremento incide de manera directa en la frecuencia e intensidad de aquéllas 5 ; a través del sistema sanitario, esas enfermedades pueden ser prevenidas (medicina preventiva) y, en aquellos casos en los que la enfermedad se haya materializado y causado una situación de dependencia, serán controladas y tratadas de forma adecuada para evitar su agravamiento (medicina asistencial); en aquellos supuestos de patologías crónicas o múltiples, son muy frecuentes las descompensaciones, por lo que su atención sanitaria reviste una especial dificultad en el manejo asistencial (domicilio, residencia, hospital) y clínico (diferentes especialidades) de estos pacientes.

4 "Este precepto constitucional exige a los poderes públicos la adopción de medidas dirigidas a configurar el derecho a la protección de la salud como un derecho subjetivo y universal, al que tengan acceso todos los ciudadanos en condiciones de igualdad y la configuración del Sistema Nacional de Salud con unas características generales y comunes, que contengan el marco básico de los servicios sanitarios en el territorio del Estado".

${ }^{5}$ Aunque no se puede vincular la enfermedad con la vejez, porque no todos los ancianos están enfermos, lo cierto es que a mayor edad, las posibilidades de padecer alguna enfermedad son más altas.
Ante dicha conexión, es interesante proceder al estudio de los mecanismos sanitarios con los que se ha venido atendiendo a las personas en situación de dependencia, determinar si el sistema de protección más adecuado para responder a esta compleja situación de necesidad sería el sanitario y analizar la remodelación que precisa este sistema para adaptarse a la nueva dimensión del riesgo tras los cambios sociales y demográficos de las últimas décadas. Todo ello, sin olvidar que nos encontramos ante una situación de necesidad que precisa, para su protección global, de un conjunto polivalente de instrumentos, no sólo de la asistencia sanitaria.

Al objeto de hacer efectivo el derecho a la salud reconocido en el artículo 43 de la Constitución, se aprueba la Ley 14/1986, de 25 de abril, General de Sanidad, con la que se consagra el Sistema Nacional de Salud. Su contenido se dirige principalmente a la promoción de la salud, prevención y curación de enfermedades, a la rehabilitación funcional de los pacientes y a su reinserción social (Zabarte, 2006), y en ella se propugna la noción de atención primaria como primer nivel de contacto de los ciudadanos con el sistema de salud (art. 12), que, sin embargo, sólo se refiere a cuestiones relacionadas con la dependencia de forma indirecta. La citada Ley fue desarrollada por el Real Decreto $63 / 1995$, de 20 de enero, sobre ordenación de las prestaciones sanitarias del Sistema Nacional de Salud (ya derogado), donde se relacionaban las prestaciones sanitarias que debían ser facilitadas directamente a las personas por el Sistema Nacional de Salud, diferenciando cinco modalidades: atención primaria, especializada, prestaciones farmacéuticas, complementarias, y servicios de información y documentación sanitaria (anexo I). En su contenido, no figuraba ninguna prestación sanitaria que, de forma directa, se dirigiera a las personas en situación de dependencia; en cambio, recogía algunas previsiones relacionadas con la dependencia de adultos y ancianos, tales como la "atención y asistencia sanitaria a enfermos con procesos crónicos", la atención a los "problemas específicos de salud durante la tercera edad, en base al artículo 50 de la Constitución" o la "atención domiciliaria a pacientes inmovilizados y terminales" (dentro de la atención primaria) [Casado Pérez, 2006: 160], aspectos todos ellos ajenos al ámbito concreto de la dependencia, pero próximos a él. Además, en su disposición adicional cuarta (actualmente vigente), se establece que "la atención a los problemas o situaciones sociales o asistenciales no sanitarias que concurran en las situaciones de enfermedad o pérdida de la salud tendrán la consideración de atenciones sociales, garantizándose en todo caso la continuidad del servicio". Este último precepto se encuentra ampliamente relacionado con la atención a la dependencia, puesto que en la práctica son frecuentes las situaciones en las que, habiéndose superado la fase aguda de una enfermedad en instalaciones sanitarias, no resulta posible su atención domiciliaria, se requiere el ingreso en residencia de servicios sociales para personas 
carentes de autonomía personal (Alonso Seco y Alemán Bracho, 2010: 131).

Especial mención merecen los programas de atención primaria relacionados con las personas dependientes, al desarrollar las actuaciones sanitarias más planificadas con relación a este colectivo. Se concretan en el programa de actividades de prevención y promoción de la salud, creado en 1988 por la Sociedad Española de Medicina Familiar y Comunitaria; el programa del anciano, dirigido a fomentar la autonomía física, psíquica y social de las personas mayores de 65 años, y que garantiza en cualquier caso la continuidad de cuidados que las personas mayores deben recibir en función de su estado de salud y nivel de riesgos al que se encuentre expuesto; y los programas de atención domiciliaria a pacientes inmovilizados y atención a terminales (Imserso, 2011: 473-477).

Por su parte, la Ley $16 / 2003$, de 28 de mayo, de cohesión y calidad del Sistema Nacional de Salud (modificada parcialmente por el Real Decreto-ley $16 / 2012$, de 20 de abril, de medidas urgentes para garantizar la sostenibilidad del Sistema Nacional de Salud y mejorar la calidad y seguridad de sus prestaciones, y por las leyes 22/2013, de 23 de diciembre, y 15/2014, de 16 de septiembre), empieza a aproximar los instrumentos sanitarios a las personas dependientes a través de la utilización de términos como cuidados de larga duración ${ }^{6}$, autonomía, enfermedades crónicas, entre otros, en el marco de las prestaciones sanitarias de atención primaria $^{7}$ y especializada ${ }^{8}$. Además, se trata de la primera Ley que introduce en España la atención sociosanitaria, incluyéndola en el catálogo de prestaciones del Sistema Nacional de Salud con el objeto de aumentar la autonomía y paliar las limitaciones de los enfermos, o lo que es lo mismo, evitar que se origine una situación de dependencia.

Sin embargo, se limita (Zabarte, 2006: 58) a señalar que en el ámbito sanitario, la atención

${ }^{6}$ Los cuidados sanitarios de larga duración hacen referencia a la atención de pacientes que precisan cuidados sanitarios, en general de baja complejidad, por procesos crónicos o por tener reducido su grado de independencia funcional para la actividad cotidiana, que pueden proporcionarse en su domicilio o requerir un periodo prolongado de internamiento (Imserso, 2011: 489).

7 El artículo 12 define la atención primaria como el nivel básico e inicial de atención que garantiza la globalidad y continuidad de la atención a lo largo de toda la vida del paciente, actuando como gestor y coordinador de casos y regulador de flujos. La atención primaria, comprende la promoción de la salud, educación sanitaria, prevención de la enfermedad, asistencia sanitaria, mantenimiento y recuperación de la salud, así como la rehabilitación física y el trabajo social. Tres años más tarde, el Real Decreto 1030/2006, de 15 de septiembre, por el que se establece la cartera de servicios comunes del Sistema Nacional de Salud y el procedimiento para su actualización, coincide en la definición de la atención primaria (anexo II).

${ }^{8}$ La atención especializada comprende actividades asistenciales, diagnósticas, terapéuticas y de rehabilitación y cuidados, así como aquéllas de promoción de la salud, educación sanitaria y prevención de la enfermedad, cuya naturaleza aconseja que se realicen en este nivel. La atención especializada garantizará la continuidad de la atención integral al paciente, una vez superadas las posibilidades de la atención primaria y hasta que aquél pueda reintegrarse en dicho nivel (art. 13 de la Ley 16/2003, de 28 de mayo). sociosanitaria comprenderá los "cuidados sanitarios de larga duración”, "la atención sanitaria a la convalecencia", y la "rehabilitación en pacientes con déficit funcional recuperable"10 (art. 14.2), ofreciendo una regulación parcial al olvidarse del ámbito social (alimentación, vivienda, ayuda de terceras personas) [Sempere Navarro, 2010: 99]. Además, las atenciones mencionadas no están incluidas en la cartera de servicios del Sistema Nacional de Salud, por lo que su disponibilidad actual para los ciudadanos queda a la libre decisión de las comunidades autónomas en función del nivel de atención que cada una determine, originando desigualdades territoriales de relevancia (Casado Pérez, 2006: 161).

No obstante, la introducción en el catálogo de prestaciones de la atención sociosanitaria pone de relieve la voluntad de los poderes públicos de impulsar la asistencia sociosanitaria, aspecto que nos brinda una dosis de optimismo en la medida en que permite confiar en que puedan satisfacerse las necesidades de un colectivo de población muy vulnerable (Zabarte, 2006: 58) garantizando la continuidad del servicio entre los servicios sanitarios y sociales a través de la adecuada coordinación entre las administraciones implicadas (art. 14.3) [Imserso, 2011: 489].

Esta Ley ha sido desarrollada por el Real Decreto 1030/2006, de 15 de septiembre, por el que se establece la cartera de servicios comunes del Sistema Nacional de Salud y el procedimiento para su actualización. En su anexo II, recoge la cartera de servicios comunes de atención primaria, entre los que cabe destacar, por su relación con la materia que nos ocupa, los siguientes: la atención al adulto, grupos de riesgo y enfermos crónicos (6.4); atención domiciliaria a pacientes inmovilizados (6.4.3); atención al anciano de riesgo, lo que implica la valoración clínica, sociofamiliar y del grado de dependencia para las actividades de la vida diaria (6.5.3); la atención domiciliaria a personas mayores inmovilizadas, (6.5.4); la atención a la salud mental de las personas con trastorno grave y prolongado y a sus cuidadores en coordinación con los servicios de atención especializada (8).

Una vez analizados los diferentes preceptos normativos del sistema sanitario y detectados sus mecanismos de protección a las personas en situación de dependencia, podemos reflexionar sobre si a través de este Sistema, en su configuración actual, se podría proteger el conjunto de necesidades que lleva implícito un estado de dependencia.

9 La atención sanitaria a la convalecencia se dirige a personas que tras sufrir un proceso agudo de enfermedad o accidente, o un episodio intercurrente en casos de enfermedad o discapacidad crónica, presentan limitaciones en su autonomía y requieren atención y cuidados durante un proceso de tiempo limitado (Imserso, 2011: 489).

${ }^{10}$ La rehabilitación de pacientes con déficit funcional recuperable se orienta a la recuperación de la autonomía perdida, y a la prevención de situaciones de discapacidad y dependencia. 
En la actualidad, y pese a la realidad manifiesta de que los servicios sanitarios constituyen en sí mismos un elemento fundamental para la protección de las personas dependientes, existen razones de peso que desaconsejaron la inclusión de la atención integral de la dependencia en el sistema de salud (González Ortega, 2013: 29; Sempere Navarro, 2010: 100; Alonso Seco y Alemán Bracho, 2010: 156-157): la amplia complejidad del sistema sanitario se vería agravada si se le añadieran prestaciones adicionales para las que habría que proporcionar recursos diferentes; el sistema de salud ya contempla prestaciones dirigidas a personas en situación de dependencia, centradas principalmente en enfermedades crónicas y cuidados médicos o de enfermería de larga duración, pero con un desarrollo reducido de la atención sanitaria especializada y dirigida a las personas dependientes, de forma que con frecuencia sus problemas acaban derivados hacia unidades o servicios relacionados con una de las patologías que sufren, más que con su situación personal (Sempere Navarro, 2010: 100); las situaciones de dependencia deben atenderse mediantes prestaciones de servicios y económicas, mientras que el sistema sanitario tan sólo se centra en los servicios, con un notable déficit de la infraestructura hospitalaria específicamente diseñada para las personas dependientes que requieran internamiento y con un reducido número de centros de atención no hospitalaria (centros de día, rehabilitación o acogida); el único recurso realmente utilizable en la mayoría de los casos es el ingreso en hospitales, mientras que un mayor desarrollo de la asistencia sanitaria a domicilio sería más conveniente para las personas dependientes, al permitir su permanencia en su entorno habitual y más rentable para el sistema sanitario (López Casasnovas y Mosterín, 2008: 49; Pérez Ortiz, 2012: $154)^{11}$; la asistencia sanitaria en España tiene un carácter gratuito (aunque con algunas observaciones tras la aprobación del Real Decreto-ley 16/2012), que si se hubiera aplicado a la atención de la dependencia, habría supuesto la insostenibilidad de la prestación; además, no es aconsejable equiparar las nociones de persona dependiente con la de enfermo, al no tratarse de una relación que siempre se produzca.

En definitiva, pese a la relación existente entre determinadas actuaciones sanitarias dirigidas a atender cuestiones estrechamente vinculadas a las situaciones de dependencia, no se puede decir ni que la noción de dependencia se haya integrado de forma suficiente en el Sistema Nacional de Salud español (Alonso Seco y Alemán Bracho, 2010:

${ }^{11}$ López Casasnovas y Mosterín (2008: 49) afirman que lo que provoca un crecimiento en el gasto sanitario no es tanto el envejecimiento de la población en sí mismo, como la respuesta asistencial que se le dé. Pérez Ortiz (2012: 154) entiende que el sistema sanitario debe reformularse para dar respuesta a una sociedad envejecida, al aumento de la prevalencia de enfermedades crónicas, de forma que no se use el sistema sanitario para atender problemas que no sean estrictamente sanitarios en las personas mayores, residiendo la solución en la puesta en marcha de sistemas de coordinación entre especialidades sanitarias y de éstas con los servicios sociales.
123), por las razones expuestas, ni que el sistema sanitario pueda cubrir las múltiples cuestiones que una situación de dependencia encierra, ya que la atención a la dependencia, además de tener un evidente componente sanitario, también requiere la intervención de los servicios sociales.

Esto no significa que la rama sanitaria deba quedar al margen del sistema protector de las situaciones de dependencia, pero sí que deberá adecuarse a las enormes transformaciones de la sociedad para responder de forma adecuada a las necesidades que plantean las situaciones de dependencia, que afectan a un número muy importante de ciudadanos que requieren de servicios asistenciales centrados en los cuidados y no sólo en la curación (Rodríguez Rodríguez, 2006: 47). Con esta finalidad, y pese a la extensión, perfección y desarrollo del sistema sanitario, es importante emprender medidas dirigidas a los siguientes cometidos (Beltrán Aguirre, 20: 4; Rodríguez Rodríguez, 2006: 48):

- Asumir la adecuada atención de las personas en situación de dependencia mediante el desarrollo y extensión de la atención geriátrica (ibídem: 70).

- Desarrollar ampliamente la atención sanitaria en geriatría en los diferentes territorios del Estado de forma coordinada.

- Ampliar los programas de formación continuada, incluyendo contenidos sobre geriatría, gerontología y discapacidades, sobre todo entre los equipos de atención primaria para intervenciones preventivas y asistenciales.

- Definición de sistemas estables de coordinación con los servicios sociales en la atención domiciliaria, en la ambulatoria (centros de día, fundamentalmente) y en las residencias y otros alojamientos (Sempere Navarro, 2010: 100).

- Compromiso para garantizar la adecuada atención sanitaria a las personas en situación de dependencia, que viven en residencias u otro tipo de alojamientos dependientes de los servicios sociales, para lo que es urgente el desarrollo de la Ley de Cohesión y Calidad.

- Desarrollar programas de rehabilitación y de mantenimiento para personas con discapacidades.

\section{La atención a la dependencia en el sistema de servicios sociales}

La atención a las personas en situación de dependencia siempre ha sido un ámbito de intervención de los servicios sociales (asistencia social interna), en un principio de forma indirecta, al centrarse en sectores concretos, como las personas con discapacidad o las personas mayores y posteriormente al dirigir su atención de forma específica a las personas en situación de dependencia. Sea como fuere, su actuación ha sido pionera en instrumentar ayudas económicas y en la 
construcción de una red de servicios (constituida por la ayuda a domicilio, la teleasistencia, los centros de día los o centros residenciales) orientada a los diferentes colectivos en situación de dependencia (personas discapacitadas física o psíquicamente, personas mayores, personas con enfermedad mental).

Así, entre las políticas sociales dirigidas a las personas con discapacidad en España, debe aludirse, en primer lugar, a la Ley 13/1982, de 7 de abril, de integración social de los minusválidos (LISMI) [derogada por el Real Decreto Legislativo 1/2013, de 29 de noviembre, por el que se aprueba el Texto Refundido de la Ley General de derechos de las personas con discapacidad y de su inclusión social], que desarrolló el artículo 49 de la Constitución. Nos encontramos ante un hito histórico en lo referente a atención sanitaria y social de las personas mayores y discapacitadas, que integra dentro de su sistema de prestaciones sociales y económicas una prestación directamente relacionada con la dependencia, llamada subsidio por ayuda de tercera persona (art. 12.2.c LISMI, actualmente regulado en el artículo 8.3 y en la disposición transitoria única del Real Decretoley $1 / 2013)$, cuyo contenido es similar al mencionado respecto a la gran invalidez, la prestación no contributiva de invalidez o la prestación no contributiva por hijo a cargo.

Este sistema especial de prestaciones fue desarrollado en su integridad por el Real Decreto $383 / 1984$, de 1 de febrero, en el que se dispuso que "el subsidio por ayuda de tercera persona consistirá en una prestación económica de carácter periódico, destinada a aquellas personas afectadas por una minusvalía que, a consecuencia de pérdidas anatómicas o funcionales, necesiten, a juicio del equipo multiprofesional, la asistencia de otra persona para realizar actos esenciales de la vida, tales como vestirse, desplazarse, comer o análogos" (art. 22). Para beneficiarse de dicha protección, deberán reunirse una serie de requisitos, tales como ser mayor de 18 años, estar afectado por una minusvalía en grado igual o superior al $75 \%$ y no hallarse atendido en centros en régimen de internamiento ${ }^{12}$.

Del mismo modo, en el marco de los servicios sociales para personas con discapacidad, la Ley $51 / 2003$, de 2 de diciembre, de igualdad de oportunidades, no discriminación y accesibilidad universal de las personas con discapacidad (derogada por el Real Decreto Legislativo 1/2013, de 29 de noviembre), introdujo una relevante modificación del artículo 46.3 del Estatuto de los Trabajadores de 1995, de una gran trascendencia para el colectivo que se estudia, al establecer que:

${ }_{12}$ Estos subsidios fueron suprimidos por la Ley 26/1990, de 20 de diciembre (disposición adicional novena), pero continúan vigentes para aquellos beneficiarios que los tuvieran reconocidos con anterioridad y no hubieran pasado a percibir una pensión no contributiva. Ahora bien, son incompatibles con las prestaciones no contributivas y con las asignaciones por hijo a cargo minusválido (Real Decreto 357/1991, art. 18, y Real Decreto 356/1991, art. 8.3).
También tendrán derecho a un período de excedencia, de duración no superior a un año, salvo que se establezca una duración mayor por negociación colectiva, los trabajadores para atender al cuidado de un familiar, hasta el segundo grado de consanguinidad o afinidad, que por razones de edad, accidente, enfermedad o discapacidad no pueda valerse por sí mismo, y no desempeñe actividad retribuida ${ }^{13}$.

En las políticas sociales hacia las personas mayores en España, es preciso remontarse a la Orden de 19 de marzo de 1970, en la que se estableció el Servicio Social de Asistencia a los Ancianos, que recogía diversas modalidades prestacionales de relevancia para las personas en situación de dependencia, tales como la atención a domicilio, los hogares y la creación y mantenimiento de centros gerontológicos y residenciales. Por su parte, el Plan Nacional de la Seguridad Social de Asistencia a los Ancianos ${ }^{14}$, aprobado por Orden de 25 de febrero de 1971, recogía la prestación de ayuda a domicilio, que comprendía el aseo personal y la limpieza del hogar, el lavado de ropa, la asistencia médica a domicilio, el servicio de comida, la mejora del hogar, la compañía a personas enfermas, la terapia ocupacional, la asistencia social, moral y jurídica, el servicio de peluquería y la biblioteca (en el marco de los servicios sociales de acción directa); la creación de hogares y clubes de pensionistas - actualmente conocidos como centros de día-, con la finalidad de favorecer la convivencia o la atención geriátrica, recreativa y cultural (servicios sociales intermedios); e incluso a la creación de residencias asistidas para quienes no pudieran valerse por sí mismos (Aznar López, 2001: 52-53).

Igualmente, han tenido una innegable importancia los planes de atención a las personas mayores y personas con discapacidad. En 1987, se aprueba el Plan Concertado de Prestaciones Básicas de Servicios Sociales, promovido por el Ministerio de Trabajo, con carácter universal para todas las personas en situación de necesidad, prestaciones dotadas de contenido informativo y asistencial (ayuda a domicilio, alojamiento alternativo, prevención e inserción social y centros de atención básica) [Montoya Melgar, 2007: 40], con el objeto final de conformar un sistema público de servicios sociales adaptados a las necesidades actuales, tal y como se manifestó en la Ponencia Técnica de Evaluación del Plan Concertado, y especialmente con la intención de ordenar globalmente el problema de la dependencia. En 1991, el Imserso (en su momento, Inserso) elaboró el primer Plan Gerontológico Nacional, que representa el desencadenante de numerosos planes gerontológicos autonómicos (Monereo Pérez et al.,

${ }^{13}$ En el ámbito público, se le ha dado la misma redacción para modificar el art. 29. 4 de la Ley de Medidas de Reforma de la Función Pública de 1984, salvo la referencia a los trabajadores, que se sustituyen por los funcionarios, y la falta de alusión a la negociación colectiva.

${ }^{14}$ En 1974, pasó a denominarse Servicio de Asistencia a Pensionistas de la Seguridad Social, por Orden del Ministerio de Trabajo, de 5 de abril. 
2010: 102). Aunque no fue publicado en el Boletín Oficial del Estado, a partir de dicho año se fueron consignando créditos en los Presupuestos Generales del Estado, distribuidos entre las comunidades autónomas (que aportaban la misma cantidad económica financiada por el Estado), con el objeto de atender a las personas mayores y especialmente a aquellas que se encontraran en situación de dependencia. Los programas se dirigen a la construcción, adaptación y mantenimiento de plazas asistidas en residencias y centros de día, destinadas a personas mayores de 65 años afectadas por graves problemas de autonomía funcional, y a la atención socioasistencial de personas dependientes afectadas por la enfermedad de alzhéimer o demencias de características similares.

Una década más tarde, fue sustituido por el Plan de Acción para las Personas Mayores 2003-2007 (Imserso, 2003) ${ }^{15}$, en el que se hacen referencias más concretas a la atención de la dependencia. Uno de sus objetivos es el de "avanzar en las políticas de protección a las personas mayores en situación de dependencia" mediante cuatro estrategias: establecer medidas de apoyo a las personas mayores en situación de dependencia, con los programas existentes; avanzar hacia una atención coordinada entre los servicios sociales y sanitarios; profundizar en las exigencias del Derecho y de la bioética a fin de salvaguardar al máximo la dignidad de las personas mayores; y promover la atención especializada a los enfermos de alzhéimer y otras demencias, así como aquellas otras patologías que requieran una atención especializada. En una línea similar se pronuncia el II Plan de Acción para las Personas con Discapacidad 2003-2007 (Imserso, 2003) ${ }^{16}$, en el que se establece que "los programas deberán dirigirse de forma preferente hacia las personas con discapacidad física severamente afectadas, aunque también podrán ser incluidas la discapacidad psíquica y sensorial en función de las necesidades de cada comunidad autónoma”.

Pero sin ninguna duda, la configuración de los servicios sociales en España y la mayor aportación en materia de dependencia, se produce en el seno de las comunidades autónomas, al ser éstas las competentes en la legislación y gestión de los servicios sociales (asistencia social externa).

Las comunidades autónomas han desempeñado, tanto con antes como después de la aprobación de la Ley de Dependencia, un papel fundamental en protección de las personas dependientes. Hasta la aprobación de la Ley 39/2006, la tutela pública de la dependencia prácticamente había quedado en el ámbito de las comunidades autónomas, que, en ejercicio de su competencia exclusiva en materia de asistencia social, fueron asumiendo a través de sus

${ }^{15}$ Aprobado por el Consejo de Ministros de 29 de agosto de 2003.

${ }^{16}$ Aprobado por el Consejo de Ministros de 5 de diciembre de 2003. Fue remplazado por el III Plan de Acción 2009-2012, aprobado por el Consejo de Ministros de 10 de julio de 2009. respectivos estatutos de autonomía la competencia de servicios sociales, con anclaje constitucional en el art. 148.1.20 de la Constitución. En cambio, con la promulgación de la Ley, la competencia exclusiva recae sobre el Estado (art. 149.1.1르 de la Constitución) para regular las condiciones básicas, sin perjuicio de la colaboración y participación de las comunidades autónomas como elemento fundamental para la gestión del Sistema para la Autonomía y la Atención a la Dependencia (Durán Bernardino, 2013).

Así, el sistema de servicios sociales, a través de sus numerosas prestaciones dirigidas a la protección de las personas en situación de dependencia, ha desarrollado una auténtica red de servicios centrada en servicios de ayuda a domicilio para la adecuación e higiene del hogar del dependiente, la compra de preparación de alimentos, el auxilio en la higiene personal o en la gestión cotidiana, la teleasistencia como instrumento de comunicación y ayuda constante entre el sujeto dependiente y el centro de atención, los centros de día o para estancias diurnas, las residencias asistidas y los centros de atención continuada, las ayudas para el equipamiento o la adaptación de los hogares de las personas dependientes (Maldonado Molina, 2003: 49; Blasco Lahoz, 2013: 59; González Ortega, 2013: 134), dirigidos tanto a las personas en situación de dependencia como a sus cuidadores, ya que venían a sustituir los cuidados familiares tradicionales, propios del arraigado modelo mediterráneo de atención a la dependencia en España.

Dadas las numerosas medidas emprendidas por el sistema de servicios sociales para atender las situaciones de dependencia y el grado de desarrollo alcanzado, se contempló la protección de la dependencia dentro del sistema público de servicios sociales, como cuarto pilar del sistema de protección del Estado del bienestar ${ }^{17}$, en el que se garantice unos servicios coordinados, suficientes y de calidad, y establezca el régimen de acceso real y efectivo a éstos. Ahora bien, no es cuestión baladí la inclusión de la protección de la dependencia en el sistema de servicios sociales, porque concurren algunos problemas que dificultan dicha integración (Alonso Seco y Alemán Bracho, 2010: 162-163): tradicionalmente los servicios sociales sólo se han dirigido a los grupos poblacionales con menores recursos económicos y la protección de la dependencia requiere atender a toda la población (Casado Pérez, 2006: 159); la atención a la dependencia debe configurarse como derecho subjetivo de ciudadanía, más allá del carácter discrecional que han tenido la mayor parte de las prestaciones de servicios sociales, cuya protección está sujeta a disponibilidades presupuestarias; los servicios sociales son competencia de las

${ }_{17}$ Ésta fue una de las conclusiones a la que se llegó en las XXIII Jornadas de Coordinación de Defensores del Pueblo Estatal y Autonómicos, celebradas en Oviedo en octubre de 2008 , basada en la integración de la atención a la dependencia en los servicios sociales autonómicos, como sistema único. 
comunidades autónomas y de las entidades locales, lo cual puede plantear problemas de unificación normativa en el reconocimiento del derecho a prestaciones de dependencia e importantes desequilibrios entre los distintos territorios (Sancho Castiello y De la Pezuela Pinto, 2002); la gestión pública de los servicios sociales está bastante diversificada, como consecuencia de una distribución competencial heterogénea; los servicios sociales siempre han tenido problemas de financiación para atender la gran demanda que reciben proveniente de amplios sectores sociales (Rodríguez Cabrero, 2004: 23; González Ortega, 2013: 135).

Finalmente, aunque el legislador de la Ley de Dependencia crea un sistema autónomo, al que denomina Sistema para la Autonomía y Atención a la Dependencia, en el contenido de sus preceptos se aprecian referencias a los servicios sociales, en las que queda patente su conexión y donde se pretende superar algunas de las carencias mencionadas para la protección de este colectivo (exposición de motivos, art. 3.0, 14.2, 16.1 y 29.1) [Alemán Bracho y Alonso Seco, 2011: 989].

De este entramado técnico-jurídico, se desprende la intención del legislador de incardinar la atención de las personas en situación de dependencia al sistema autonómico de servicios sociales, al recoger entre sus principios la integración de las prestaciones establecidas en la Ley de Dependencia en las redes de servicios sociales de las comunidades autónomas.

Lo que sin duda es indiscutible es que el nuevo sistema se desenvuelve en el marco del sistema de servicios sociales español (Rodríguez Cabrero, 2007), constituyendo en sí mismo una magnífica oportunidad para ampliar y modernizar la acción protectora de los servicios sociales y para la renovación general de los servicios, elevando sus estándares de calidad, la formación de los profesionales y las condiciones de trabajo de sus empleados (Martín Pindado, 2007: 83; Alemán Bracho y Alonso Seco, 2011: 164).

\section{La cobertura privada e informal de las situaciones de dependencia}

La protección de las personas en situación de dependencia no se agota en la esfera pública, sino que, como a continuación se comprobará, el ámbito privado, constituido por el mercado y los cuidados incesantes de la familia, han tenido una presencia crucial en la atención de este colectivo. La intervención de estos dos ámbitos en la protección de las personas en situación de dependencia siempre ha existido y en la actualidad cobra especial importancia con el objeto de suplir las carencias de una protección social pública cada vez más deficitaria (La Casa García, 2012: 10).
4.1. Configuración del modelo de protección social de la dependencia. Entre lo público y lo privado

Con la aprobación de la Ley 39/2006, de 14 de diciembre, de Promoción de la Autonomía Personal y Atención a las Personas en Situación de Dependencia, se aboga por el establecimiento de un sistema público y universal de protección, en el que los instrumentos privados de protección, lejos de ocupar una función central o única en la protección de la dependencia, se configuran como mecanismos complementarios de la acción protectora básica de carácter público (Monereo Pérez y Fernández Bernat, 2008: 738).

La decisión del legislador de la Ley de Dependencia viene justificada por argumentos funcionales y sociales, ampliamente razonables (Monereo Pérez et al., 2010: 282): en primer lugar, porque los instrumentos privados de previsión carecen de los medios para responder a la amplitud de problemas que plantean los cuidados de larga duración (Hernández González, 2009: 41; Rodríguez Cabrero, 2004: 250; Mercader Ugina y Muñoz Ruiz, 2004: 859); y, en segundo lugar, porque esta opción privatizadora dejaría sin protección a muchas personas en situación de dependencia, no sólo por la oferta de productos, limitada a cubrir determinados riesgos, sino también por la escasa demanda, motivada por la baja sensibilidad al riesgo de la dependencia y el alto coste de su cobertura privada. Sirva como ejemplo lo ya sucedido en el mercado español (Maldonado Molina, 2003: 79-80).

En definitiva, el legislador de la Ley de Dependencia, consciente del reto titánico que pretende asumir ha considerado que la atención a las personas en situación de dependencia exige una combinación de esfuerzos públicos y privados (González de Frutos, 2006: 21-22), pero partiendo de la base de que la acción protectora básica, mínima y obligatoria debía ser de carácter estatal para dar una respuesta eficaz a este problema social (Monereo Pérez et al., 2010: 292), a sabiendas de que la cobertura o respuesta desde el ámbito privado no puede ni pretende ofrecer una cobertura universal e integral (Veiga Copo, 2008: 11). Así, la actuación pública se desarrollará en torno a un eje básico, a saber, una red de utilización pública que coordina los centros y servicios, públicos y privados (art. 6.2 de la Ley de Dependencia): el Sistema para la Autonomía y Atención a la Dependencia.

\subsection{La participación de la iniciativa privada en el sistema de protección social de la dependencia}

A pesar del carácter secundario que la Ley de Dependencia confiere a los instrumentos privados de previsión, su intervención no es nada desdeñable si se atiende a las numerosas e importantes referencias que en su contenido se hace al ámbito privado. Entre otros motivos, porque si se quiere garantizar la igualdad en el ejercicio del derecho subjetivo 
de ciudadanía a la promoción de la autonomía personal y atención a las personas en situación de dependencia, será necesaria no sólo la "participación de las personas en situación de dependencia y, en su caso, de sus familiares y entidades que les representen", sino también "la participación de la iniciativa privada en los servicios y prestaciones de promoción de la autonomía personal y atención a la situación de dependencia” [art. 3.k y 3.m)], evitando así que los recursos públicos sean utilizados por personas que disponen de capacidad económica para atender su propia situación de dependencia.

En su exposición de motivos, se reconoce que el Sistema para la Autonomía y Atención a la Dependencia "sirve de cauce para la colaboración y participación de las Administraciones Públicas y para optimizar los recursos públicos y privados disponibles" y se prevén las modificaciones legislativas necesarias para la regulación de la cobertura privada de esta contingencia. Entrando en el articulado de la Ley, se considera un principio rector de la norma "la participación de la iniciativa privada en los servicios y prestaciones de promoción de la autonomía personal y atención a la situación de dependencia”. Este reconocimiento expreso debe ser subrayado, ya que a través de él se incentiva la intervención de los mecanismos privados en la cobertura de las situaciones de dependencia. El legislador, consciente de la importante actuación de los centros privados concertados en la red de servicios del Sistema, hace continuas referencias a aquéllos en numerosos preceptos (art. 3.0, 6.1 y 2, $14.2,16.1$ y $2,17.1$.

Pero sin duda alguna, la mayor intervención de la oferta privada se produce por vía indirecta, a través de la participación de los beneficiarios en el coste de las prestaciones (art. 33), aunque ésta dependerá de los recursos económicos de los que disponga y del tipo y coste del servicio (Duque Santamaría y Urrutia Santos, 2006-2007: 448).

Fuera del cuerpo de la norma, encontramos la mención más concreta y precisa a la cobertura privada. En la disposición adicional séptima, titulada 'Instrumentos privados para la cobertura de la dependencia', se establece una previsión de desarrollo de la cobertura privada de las situaciones de dependencia en dos aspectos. En su apartado uno, se hace alusión a la cobertura privada de las situaciones de dependencia en los siguientes términos: "el Gobierno, en el plazo de seis meses, promoverá las modificaciones legislativas que procedan, para regular la cobertura privada de las situaciones de dependencia”; sin embargo, no se concreta el tipo de instrumento privado de protección que podrán actuar en la cobertura de la dependencia. En su apartado dos, igualmente se impone un mandato al Gobierno para que impulse una regulación fiscal de aquellos mecanismos privados acorde con el principio de copago impuesto en la Ley, al disponer que "con el fin de facilitar la cofinanciación por los beneficiarios de los servicios que se establecen en la presente Ley, se promoverá la regulación del tratamiento fiscal de los instrumentos privados de cobertura de la dependencia", careciendo igualmente de concreción, al no determinar los medios precisos y la finalidad de la regulación que se pretende (Monereo Pérez et al., 2010: 286).

El mandato impuesto al Gobierno se vio satisfecho, no a los seis meses, como estaba previsto, pero sí al año de la aprobación de la Ley de Dependencia. Concretamente, el 8 de diciembre de 2007 se publica en el BOE la Ley 41/2007, de 7 de diciembre, por la que se modifica la Ley $2 / 1981$, de 25 de marzo, de Regulación del Mercado Hipotecario y otras normas del sistema hipotecario y financiero, de regulación de las hipotecas inversas y el seguro de dependencia y por la que se establece determinada norma tributaria (modificada recientemente por la Ley $1 / 2013$, de 14 de mayo, de medidas para reforzar la protección a los deudores hipotecarios, reestructuración de deuda y alquiler social), que entra en vigor el 9 de diciembre y constituye, en la actualidad, el principal marco de desarrollo de las previsiones contenidas en la disposición adicional séptima de la Ley 39/2006 de 14 de diciembre, en relación con los instrumentos privados que pueden destinarse a la cobertura de la dependencia y a su tratamiento fiscal.

Queda así reflejado en el articulado de la Ley de Dependencia la preocupación del legislador por hacer partícipe a la iniciativa privada en el sistema de protección social de la dependencia.

Participación que se evidencia en la realidad práctica, ya que las recientes políticas de austeridad favorecen claramente la participación del mercado en la protección de las personas en situación de dependencia a través de las prestaciones contempladas en la Ley, especialmente, la prestación económica vinculada al servicio (Durán Bernardino, 2014: 190-196).

\subsection{Instrumentos privados de cobertura de las situaciones de dependencia}

Para que las personas puedan hacer frente a los gastos de cobertura cuando le sobrevenga una situación de dependencia, se han ido creando numerosos mecanismos de atención privada para la cobertura de la dependencia, a través de los cuales se prevé dicha contingencia y se asegura cuando dicha situación se materialice. En lo que sigue, se analizan los instrumentos de mayor proyección.

\subsubsection{Seguro de dependencia}

En desarrollo a lo establecido en su disposición adicional séptima, la Ley 41/2007, de 7 de diciembre, determina que la primera fórmula de aseguramiento de la contingencia de la dependencia se instrumentará a través de un contrato de seguro, definido como 
"aquel que obliga al asegurador, para el caso de que se produzca la situación de dependencia, conforme a lo dispuesto en la normativa reguladora de la promoción de la autonomía personal y atención a las personas en situación de dependencia, y dentro de los términos establecidos en la ley y en el contrato, al cumplimiento de la prestación convenida con la finalidad de atender, total o parcialmente, directa o indirectamente, las consecuencias perjudiciales para el asegurado que se deriven de dicha situación”. El contrato de seguro de dependencia será suscrito con entidades aseguradoras, incluidas las mutuas de previsión social, que cuenten con la preceptiva autorización administrativa y demás requisitos necesarios para el desarrollo de la actividad aseguradora en España en los ramos de vida o enfermedad (disposición adicional segunda), lo que permite que este instrumento privado pueda intervenir sin ningún obstáculo en el ámbito de los cuidados de larga duración.

Entre los aspectos esenciales del seguro privado de dependencia, cabe analizar los siguientes:

- En primer lugar, dicho seguro se podría configurar como un seguro sobre las personas, ya que cubre riesgos relacionados con la existencia, integridad corporal o salud de los asegurados, pero con la peculiaridad de que, al configurarse la dependencia como un nuevo riesgo, autónomo y diferenciado, se tratará de un contrato complejo integrado por el seguro de vida, de accidente, enfermedad o asistencia sanitaria, encontrándonos ante un nuevo ramo, la dependencia, que presenta rasgos específicos en el ámbito de los seguros de personas (Álvarez Rodríguez, 2004: 193).

- Un segundo elemento fundamental en el seguro de dependencia está constituido por las prestaciones otorgadas a los beneficiarios. Podría tratarse tanto de prestaciones de servicios dirigidas a satisfacer las necesidades sociales (como la ayuda a domicilio, las residencias o los centros de día), como de prestaciones económicas (reembolso de gastos y pago de capitales o rentas). Ahora bien, debe tenerse en cuenta que la Ley 39/2006 da clara prioridad a las prestaciones de servicios frente a las económicas, cuestión evaluada positivamente por los sujetos asegurados, pero que sin duda entrañará mayor dificultad para el asegurador.

- En tercer lugar, debe tenerse en cuenta que el contrato de seguro de dependencia podrá articularse tanto a través de pólizas individuales como colectivas que se realizarán en el momento en el que el asegurado o sus beneficiarios cumplan con los requisitos establecidos en la Ley de Dependencia, por los que se adquiere la condición de dependiente, pudiendo preverse en el propio contrato cuándo se considera que la persona ha adquirido tal condición, como bien establece la disposición adicional segunda de la Ley 41/2007, de 7 de diciembre.
Por sus características concretas, se puede afirmar que el seguro es el instrumento más idóneo para la cobertura privada de la dependencia, al ser el único que puede ofrecer cobertura en sentido estricto y gestión del riesgo de dependencia. Los elementos descriptivos del riesgo de dependencia hacen que su gestión pueda realizarse de forma eficiente a través del seguro al tratarse de una contingencia que no se sabe si se va a producir, se desconoce el momento en el que se producirá, no se sabe la intensidad o gravedad con la que se presentará y no se puede diagnosticar a priori su posible reversibilidad o agravamiento (Duque Santamaría y Urrutia Santos, 2006-2007: 452).

Ahora bien, a pesar de la idoneidad de este instrumento privado para la cobertura de las situaciones de dependencia, lo cierto es que los servicios privados de dependencia se han venido caracterizando desde sus orígenes - pioneros como han sido en la cobertura del riesgo de la dependencia (Maldonado Molina, 2003: 66-69)- por notorias dificultades en su implantación en el mercado. De forma que, a pesar de tratarse de una buena oportunidad de negocio para las aseguradoras, su desarrollo se ha visto limitado por diferentes obstáculos:

- Las entidades aseguradoras presentan algunas dificultades para ofrecer prestaciones adecuadas a la necesidad que pretende proteger, debido a la complejidad del producto.

- Su función de complementar y completar la cobertura pública en aquellos aspectos donde ésta no llega o lo hace de forma ineficiente difícilmente se podrá cumplir (Veiga Copo, 2008: 12).

- La población es poco sensible a la percepción del riesgo de la dependencia, al tratarse de una contingencia que suele producirse a una edad muy elevada (Veiga Copo, 2008: 31).

- A edades tempranas, el riesgo de dependencia es percibido como algo lejano, y cuando se percibe como un riesgo cercano a edades avanzadas, la prima es demasiado elevada y el mercado asegurador sólo resuelve una parte de las demandas de cuidados (Blasco Lahoz, 2013: 1098).

- En España existe poca cultura aseguradora, especialmente ante productos tan novedosos como la dependencia (Álvarez Rodríguez, 2013: 165).

- Existen factores coyunturales, externos, que influyen en la estrategia y control del negocio.

- El posible solapamiento o desajuste con la cobertura ofrecida por el Estado.

Para salvar dichas dificultades, el sector considera imprescindible el establecimiento de incentivos fiscales para alentar la contratación de dichos seguros. A esta consideración da respuesta la Ley $35 / 2007$, de 28 de noviembre, aunque limitando tal fiscalidad a la cobertura del riesgo de dependencia severa o gran dependencia (al igual que los planes 
de pensiones). Aunque el sector asegurador ha percibido positivamente estas medidas, lo cierto es que siguen resultando insuficientes de cara a hacer más atractiva esta nueva figura de ahorro-previsión (Monereo Pérez y Fernández Bernat, 2008: 156-157), ya que ni fomentan ni dificultan la contratación de este producto.

Ahora bien, la situación actual de crisis financiera generalizada, junto con las medidas políticas adoptadas, están provocando un giro en el escenario protector expuesto. El Sistema para la Autonomía y Atención a la Dependencia se encuentra ante graves problemas para su implantación, derivados de la insuficiencia de recursos financieros (destinados a la protección social de la dependencia por la Administración Pública) y de la falta de medios para valorar la dependencia (reflejados en los tiempos excesivos de tramitación de las solicitudes, en la valoración y en el reconocimiento de la prestación). Estas dificultades representan una brecha en el Sistema que las compañías aseguradoras están sabiendo aprovechar para entrar en el mercado asegurador de la dependencia, ofreciendo prestaciones económicas más ajustadas al coste y prestaciones de servicios de calidad (Martín-Gijón Machuca, 2012: passim).

\subsubsection{La hipoteca inversa}

La hipoteca inversa se define, de forma precisa, en la exposición de motivos de la Ley 41/2007, de 7 de diciembre, como

Préstamo o crédito hipotecario del que el propietario de la vivienda realiza disposiciones, normalmente periódicas, aunque la disposición pueda ser de una sola vez, hasta un importe máximo determinado por un porcentaje del valor de tasación en el momento de la constitución. Cuando se alcanza dicho porcentaje, el mayor o dependiente deja de disponer de la renta y la deuda sigue generando intereses. La recuperación por parte de la entidad del crédito dispuesto más los intereses se produce normalmente de una vez cuando fallece el propietario, mediante la cancelación de la deuda por los herederos o la ejecución de la garantía hipotecaria por parte de la entidad de crédito.

Este instrumento implica que las personas dependientes podrán hacer uso de su vivienda habitual para obtener un préstamo hipotecario sobre dicho inmueble, cuando necesiten un complemento económico para atender su situación de dependencia. Dicho préstamo se extenderá hasta el momento en que fallezca o hasta que se pueda satisfacer su necesidad por cualquier otra vía pública o privada. A partir de dicho momento existen dos opciones, bien cancelar la deuda (por el solicitante o por los herederos) o bien la entidad de crédito podrá recuperar el crédito más los intereses con el bien hipotecado o la herencia.
Para la constitución de dicha hipoteca inversa, será necesario el cumplimiento de los requisitos impuestos por la disposición adicional primera de la Ley 41/2007, de 7 de diciembre, a saber:

- Hasta el 15 de mayo de 2013, tan sólo podían solicitarla la persona en situación de dependencia severa o gran dependencia o las personas con una edad igual o superior a los 65 años. Con la publicación de la Ley $1 / 2013$, de 14 de mayo, de medidas para reforzar la protección a los deudores hipotecarios, reestructuración de deuda y alquiler social, se modifica la letra a) del apartado 1 de la disposición adicional primera, ampliándose el ámbito subjetivo de la hipoteca inversa. Así, podrán constituir una hipoteca inversa las siguientes personas: aquellas de edad igual o superior a los 65 años; aquellas que estén afectadas de dependencia; 0 aquellas a las que se les haya reconocido un grado de discapacidad igual o superior al $33 \%$. Por lo tanto, con esta reforma se elimina la exigencia de los grados (gran dependencia o dependencia severa) y se incluyen a las personas con una discapacidad igual o superior al $33 \%$, de lo que se deduce la clara intención de fomentar la contratación de este instrumento de cobertura privada.

- El deudor dispondrá del importe del préstamo o crédito mediante disposiciones periódicas o únicas.

- La deuda sólo será exigible por el acreedor y la garantía ejecutable cuando fallezca el prestatario, o si así se estipula en el contrato, cuando fallezca el último de los beneficiarios.

- La concesión de la prestación sólo podrá efectuarla entidades de crédito y entidades aseguradoras autorizadas para operar en España, y de acuerdo con los límites, requisitos o condiciones que imponga la normativa sectorial a dicha entidad aseguradoras.

- La hipoteca inversa podrá instrumentarse sobre la vivienda habitual (apartado 1 de la disposición adicional primera) o bien sobre cualquier otro bien inmueble distinto de la vivienda habitual del solicitante (apartado 10 de la disposición adicional primera), si bien, en este último caso, no se aplicaría la normativa prevista en la propia disposición adicional primera. Esta posibilidad plantea importantes problemas en la cobertura de la dependencia (Cano Galán, 2008: 457-458).

Como fórmula incentivadora de este mecanismo de cobertura privada de la dependencia, la Ley 41/2007, de 7 de diciembre, igualmente prevé un conjunto de exenciones y reducciones a las escrituras públicas y honorarios notariales y registrales por constitución, subrogación, novación modificativa y cancelación de la hipoteca inversa.

Los requisitos exigidos para que pueda considerarse una hipoteca inversa plantean numerosos problemas para que este instrumento privado pueda ser 
utilizado por el propio interesado o solicitante para la cobertura de la contingencia de dependencia.

En sentido estricto, no puede considerarse que la hipoteca inversa sea un instrumento de cobertura, al carecer de medios de prevención o previsión. Además, su utilización no se limita a situaciones de dependencia, sino que se extiende a todas aquellas personas mayores de 65 años o con discapacidad que deseen hacer líquido su patrimonio inmobiliario.

A pesar de la regulación de esta figura privada, lo cierto es que su comercialización no ha experimentado un crecimiento significativo en el mercado español. Las razones pueden residir en que las propias entidades habilitadas para ofrecer hipotecas inversas no creen en el producto (máxime ante el actual contexto económico de deterioro del mercado inmobiliario), los numerosos litigios que pueden ocasionarse con los herederos frena la oferta, el resultante de aplicar tipos de interés elevado y porcentajes de reducción sobre el valor de tasación de la vivienda para calcular el capital máximo concedido, es un producto que ofrece una renta muy escasa y poco atractiva, existen importantes reticencias culturales sobre la liquidación del patrimonio hereditario, entre otras.

\section{La continua presencia de los cuidadores familiares}

La dependencia es, por definición, una situación en la que una persona, por su falta de autonomía física, mental intelectual o sensorial, precisa la atención de otra persona para realizar actividades básicas de la vida diaria (art. 2 de la Ley de Dependencia). Es decir, existen al menos dos sujetos implicados en la relación: el que necesita la ayuda de otra persona y el que proporciona los cuidados requeridos. Para determinar la oferta de estos cuidados que precisan las personas dependientes, es necesario analizar la forma en la que socialmente se ha ido pactando el reparto de obligaciones y responsabilidades entre los tres vértices implicados, el Estado, la familia y el mercado, teniendo en cuenta que, por su interrelación, el cambio en la implicación de uno de ellos influye en la presencia de los restantes.

A pesar de que los artículos 49 y 50 de la Constitución prevén que los poderes públicos deberán articular un sistema de servicios sociales para el bienestar de los ciudadanos, la realidad es que el cuidado de las personas en situación de dependencia ha sido asumido tradicionalmente por los familiares o por las propias personas que se encontrasen en dicha situación (Cano Galán, 2008: 446).

Durante muchas décadas, la responsabilidad de los cuidados de la dependencia tan sólo se adscribía al espacio de lo llamado privado-doméstico. Eran las familias, y especialmente las mujeres de edad media o avanzada quienes han venido soportando la atención y cuidado de sus familiares próximos en edad avanzada o que presentan alguna o algunas minusvalías que les impiden valerse por sí mismos y les aboca al mundo de la dependencia. $Y$ ese apoyo informal, necesario y no pagado, se ha venido haciendo con escasa o nula ayuda de las instituciones públicas (Estado) ni de las privadas (mercado) [Gutiérrez Resa, 2007: 87]. Ello se debe a la arraigada cultura familiar propia de un modelo mediterráneo de cuidados como el nuestro. En efecto, el peso tan relevante que tiene en nuestro país el apoyo de las familias trae como consecuencia que el Estado no asuma su responsabilidad de provisión de servicios para la atención de las personas dependientes. Dentro de este núcleo familiar de provisión de cuidados, son las mujeres, en su mayoría, hijas del dependiente, las que representan el pilar fundamental de la ayuda, las cuidadoras por excelencia, un auténtico centro de servicios para la familia, auténtico vehículo de la solidaridad familiar.

Este perfil social del cuidador se ha venido fraguando sobre la histórica división del trabajo dentro de la familia, donde la mujer producía servicios no remunerados en el hogar dirigidos a atender a sus familiares, sin reconocimiento social y carentes de cualquier protección social, mientras que los varones aportaban los ingresos obtenidos en el mercado laboral. Pero debe tenerse en cuenta que esta distribución de roles tiene graves consecuencias para la mujer en dos aspectos especialmente, lo que en su conjunto hace que este modelo tradicional de cuidados se resienta:

- En su protección social, en tanto que mientras que los varones dependientes dispondrán de más recursos institucionales, mejores pensiones, más patrimonio y más personas dispuestas a cuidarlos (como consecuencia de la mayor esperanza de vida de las mujeres y de su predisposición a los cuidados), las mujeres dispondrán de pocos recursos institucionales, por su ausencia del mercado de trabajo a lo largo de su vida, tendrán pensiones más reducidas y no dispondrán del mismo número de cuidadores predispuestos a cederles el tiempo necesario de cuidados (Durán Heras, 2006: 63).

- En sus condiciones de vida personal, por las graves repercusiones que tiene esta prevalencia de la mujer trabajadora en la atención a las personas dependientes en los diferentes ámbitos de su vida: en primer lugar, el tiempo dedicado a los cuidados del familiar dependiente (más de 40 horas a la semana, cifra que en ocasiones se duplica o triplica) y el hecho de asumir casi en exclusiva dichos cuidados les obliga a reducir su tiempo de ocio y descanso; en segundo lugar, supone un elevado coste para las familias; en tercer lugar, como consecuencia de la carga excesiva que representa física y emocionalmente los cuidados, padecen múltiples patologías, especialmente agotamiento, trastornos del sueño, dolores de espalda, ansiedad y, frecuentemente, depresión (perciben que su expectativa de vida se reduce a seguir ejerciendo de cuidador, 
sienten miedo al futuro y tienen dificultades económicas); en cuarto lugar, repercute negativamente en su vida laboral o profesional, ya que suele ser la mujer la que deje el trabajo o reduzca su jornada laboral, y en aquellos casos en los que el dependiente requiera de unos cuidados continuos, no podrá acceder al mercado laboral, renunciando a las oportunidades que éste le ofrezca. En efecto, el cuidado tiene amplias repercusiones en el desarrollo de la vida normal de los cuidadores, relacionándose con problemas de diversa índole que se ven reflejados especialmente en el cuidador principal, de ahí que se les llegue a denominar "víctimas o pacientes ocultos" (Roa Venega y Fernández Prados, 2013, 266). Por todo ello, se puede afirmar que el peso otorgado por el sistema social a las mujeres es desproporcionado e injusto, al mantener a un colectivo muy amplio de población en unas condiciones de vida mínimamente dignas (Montero Soler, 2010: 73).

Sin embargo, este sistema de apoyo informal sobre el que se ha venido asentando la atención a la dependencia en nuestro país ha empezado a quebrar. Las mujeres han venido actuando de variable de ajuste entre las demandas del mercado y las necesidades de las personas dependientes, garantizando una amplia elasticidad interna en el sistema durante muchos años, pero dicha elasticidad ha demostrado no ser infinita. Los continuos cambios demográficos y sociales están desbordando la capacidad de esta fórmula informal de cuidados, motivo por el cual se reclama una reorganización social en la protección de esta contingencia que ayude tanto a la persona dependiente como a su cuidador.

En los últimos años, los cambios sociodemográficos han venido acompañados de cambios

socioculturales, originándose lo que se conoce en el ámbito europeo como la crisis de los cuidados de larga duración, lo que ha supuesto una reducción de los cuidadores potenciales, del tiempo disponible para el cuidado de los ancianos y discapacitados $y$, en consecuencia, la inoperancia de los mecanismos tradicionales de cuidado. Estos cambios significativos en el apoyo informal han provocado una gradual y paralela ocupación de trabajadoras extranjeras (Bazo, 2012: 76-81), que por vía formal o informal del servicio doméstico, han ido asumiendo en exclusiva estas tareas de cuidado.

Rebus sic stantibus, el sistema jurídico ha de aportar una respuesta jurídica específica que atienda y promocione la autonomía personal de las personas dependientes y que proteja socialmente al cuidador familiar, dotándolo de un régimen jurídico que le confiera cierta seguridad jurídica (Fernández Orrico, 2008: 82). Con la aprobación de la Ley de Dependencia, los poderes públicos asumen la responsabilidad en la atención y cuidados de las necesidades de las personas dependientes, pero sin que esto signifique la expulsión de la actuación del sector privado en este ámbito protector -como ya se comprobó en el apartado anterior-y, en menor medida, también de los cuidadores familiares que, como se comprueba, continúan desempeñando a día de hoy una labor imperante en la atención de las personas en situación de dependencia.

En definitiva, a través del sistema normativo español de protección de la dependencia se pretende proyectar un cambio en la cultura feminista de cuidados de las personas dependientes, a través de lo que se ha venido llamando socialización del riesgo, que pretende romper con los tradicionales roles de género y entrar en conexión con el derecho fundamental de igualdad y no discriminación $e x$ artículo 14 de la Constitución.

\section{Conclusiones finales}

Durante décadas, las personas en situación de dependencia han sido atendidas en el núcleo familiar y, de forma subsidiaria, a través de diferentes mecanismos en el marco de las políticas de protección social (sistema de Seguridad Social, sistema sanitario, servicios sociales y asistencia social), proporcionándoles ayudas económicas, de servicios y cuidados personales, aunque con un carácter limitado e inespecífico.

Sin embargo, en los últimos años se han producido sustanciales transformaciones en las sociedades europeas -envejecimiento progresivo de la población, aumento de las enfermedades crónicas y de los índices de siniestralidad vial y laboral, cambios en las estructuras tradicionales de las familias- que requieren la atención de los poderes públicos para avanzar en el campo de protección social y así atender una situación de necesidad, la dependencia, que no siendo nueva, adquiriere una especial relevancia ante su generalización actual y pronóstico futuro.

Desde la perspectiva de los sistemas de protección social, nos encontramos ante una situación de necesidad en tanto que afecta a un volumen muy elevado de la población, acontece en algún momento de la vida de las personas y una vez que se materializa provoca consecuencias negativas al sujeto que la padece hasta el punto de necesitar la ayuda de otra persona para realizar las actividades básicas de la vida diaria. Rebus sic stantibus, los poderes públicos deben dar una respuesta específica, global e integrada a esta situación, para cumplir así con una exigencia constitucional, al tratarse de la protección de situaciones de necesidad (art. 41 de la Constitución) y, en particular, de la tutela especial de personas mayores (art. 50 de la Constitución) y discapacitadas (art. 49 de la Constitución).

Ante este contexto, corresponde al Estado social proporcionar a sus ciudadanos una mínima seguridad frente a las situaciones de necesidad 
en la que puedan encontrarse, facilitándoles los medios precisos para eliminar los obstáculos que les dificultan o impiden alcanzar los objetivos humanos de realización plena de la autonomía y la independencia del individuo, favoreciendo la igualdad entre todos los ciudadanos (art. 14 de la Constitución).

Sin embargo, aunque inicialmente se optara por la configuración de un sistema de protección público, universal y específico para dar cobertura a las personas en situación de dependencia, en el que se configura a la dependencia como un Derecho social de prestación, desde 2010 se está produciendo un cambio de orientación, favoreciéndose los mecanismos privados de protección, al mismo tiempo que se debilita la acción protectora del Sistema para la Autonomía y Atención a la Dependencia y se impide su desarrollo.

Todo ello es fruto de la nueva política económica de orientación pro-mercado que subyace a causa de la crisis económico-financiera actual y se viene caracterizando por la contención del gasto público, al tiempo que se favorece una mayor responsabilidad individual, lo que lleva aparejado un mayor peso del sector privado.

Ante este escenario, el Estado debe fortalecer las políticas sociales, - garantizando un nivel mínimo de seguridad vital a todos los ciudadanos-, sólo así se respetaría nuestro consolidado sistema de protección social, integrado por el sistema de Seguridad Social, Sistema Nacional de Salud y el de servicios sociales, que siempre actuarán como soportes para la atención de las personas en situación de dependencia de acuerdo con los fundamentos constitucionales que garantizarán su protección global (artículos 41, 43, 49 y 50). Se trata del soporte constitucional que, junto con el papel fundamental y tradicional ejercido por los cuidadores en la protección de este colectivo y la actuación complementaria de la iniciativa privada, se mantendrá pese a los recortes emprendidos en la materia que nos ocupa. 
ALEMÁN BRACHO, C.; y ALONSO SECO, J. M. (2011): "LOS sistemas de servicios sociales en las leyes autonómicas de servicios sociales", Revista Española de Derecho del Trabajo, no 152 , págs. 973-1.002. públicos de protección social”, en ALEMÁN ¿qué interés tiene el sector privado asegurador?", en GONZÁLEZ ORTEGA. S; y QUINTERO LIMA, M. G. (coords.), Protección La Ley, págs. 153-166. de Seguridad Social, nํㅜ 5, págs. 49-69.

BARCELÓN COBEDO, S.; y QUINTERO LIMA, M. G. (2006): "Las situaciones de dependencia personal como nueva contingencia protegida por el sistema de protección social", Revista del págs. 13-33. la dependencia, Nau Llibres, Valencia.

BELTRÁN AGUIRRE, J. L. (2008): “La atención a la dependencia: régimen legal. Interacciones vol. $16, \mathrm{n}$ - extra 2, págs. 3-27. un seguro social en construcción", Aranzadi Social, $\mathrm{n}{ }^{\circ}$ 5, págs. 1.087-1.110. Revista del Ministerio de Trabajo y Asuntos
CRUZ VILLALÓN, J. (2007): “La protección social de la dependencia”, Temas Laborales, no 89, págs. 9-26.

DURÁN BERNARDINO, M. (2014): “La prestación económica para cuidados en el entorno familiar y la protección social de los cuidadores no profesionales tras la entrada en vigor del RDLey 20/2012, de 13 de julio", Documentación Laboral, no 102, págs. 190-194. "Integración de la dependencia en los sistemas BRACHO, C; ALONSO SECO, J. M.; y FERNÁNDEZ SANTIAGO, P. (coords.), Dependencia y servicios sociales, Cizur Menor, Aranzadi, págs. 111-152.

ÁLVAREZ RODRÍGUEZ, M. (2004): "Seguro de dependencia: social de las personas dependientes, Madrid,

AZNAR LÓPEZ, M. (2001): “Notas sobre la protección de la dependencia en la Seguridad Social española. Aspectos retrospectivos y prospectivos", Foro Ministerio de Trabajo y Asuntos Sociales, no 60,

BAZO, M. T. (2012): Envejecimiento poblacional y el reto de entre lo social y lo sanitario", Derecho y Salud,

BLASCO LAHOZ, J. J. (2013): “La protección de la dependencia:

CASADO PÉREZ, D. (2006): "Expectativas de las personas mayores respecto a la Ley de Dependencia", Sociales, no 6o, págs. 149-165. distribución constitucional y legal de competencias en el modelo de protección social a la dependencia”, Aranzadi Social, no 8, págs. 206-235.

DUQUE SANTAMARÍA, L.; y URRUTIA SANTOS, A. (20062007): "Instrumentos privados de cobertura de las situaciones de dependencia", Documentación Administrativa, n- 276-277, pág. 443-468.

DURÁN HERAS, M. A. (2006): “Dependientes y cuidadores: el desafío de los próximos años", Ministerio de Trabajo y Asuntos Sociales, no 60, págs. 57-73.

ESPAÑA (2014): “Ley 15/2014, de 16 de septiembre, de racionalización del Sector Público y otras medidas de reforma administrativa", Boletín Oficial del Estado, n- 226, 17-9-14.

- (2013): “Real Decreto Legislativo 1/2013, de 29 de noviembre, por el que se aprueba el Texto Refundido de la Ley General de derechos de las personas con discapacidad y de su inclusión social”, Boletín Oficial del Estado, $\mathrm{n}-289$, 3-12-13.

- (2013): “Real Decreto Legislativo 1/2013, de 29 de noviembre, por el que se aprueba el Texto Refundido de la Ley General de derechos de las personas con discapacidad y de su inclusión social”, Boletín Oficial del Estado, nํ․289, 3-12-13.

- (2013): “Ley 22/2013, de 23 de diciembre, de Presupuestos Generales del Estado para el año 2014”, Boletín Oficial del Estado, ํㅜ 309, 26-12-13. 
- (2013): "Ley $1 / 2013$, de 14 de mayo, de medidas para reforzar la protección a los deudores hipotecarios, reestructuración de deuda y alquiler social”, Boletín Oficial del Estado, n- $116,15-5-13$.

- (2013): “Ley 1/2013, de 14 de mayo, de medidas para reforzar la protección a los deudores hipotecarios, reestructuración de deuda y alquiler social", Boletín Oficial del Estado, no $116,15-5$-13.

- (2012): “Real Decreto-ley 16/2012, de 20 de abril, de medidas urgentes para garantizar la sostenibilidad del Sistema Nacional de Salud y mejorar la calidad y seguridad de sus prestaciones", Boletín Oficial del Estado, no 98, 24-4-12.

- (2007): "Ley 41/2007, de 7 de diciembre, por la que se modifica la Ley $2 / 1981$, de 25 de marzo, de Regulación del Mercado Hipotecario y otras normas del sistema hipotecario y financiero, de regulación de las hipotecas inversas y el seguro de dependencia y por la que se establece determinada norma tributaria”, Boletín Oficial del Estado, nํ2 294, 8-12-07.

- (2006): "Real Decreto 1030/2006, de 15 de septiembre, por el que se establece la cartera de servicios comunes del Sistema Nacional de Salud y el procedimiento para su actualización", Boletín Oficial del Estado, nำ 222, 16-9-06.

- (2003): “Ley 51/2003, de 2 de diciembre, de igualdad de oportunidades, no discriminación y accesibilidad universal de las personas con discapacidad”, Boletín Oficial del Estado, no $289,3-12-03$.

- (2003): "Ley 16/2003, de 28 de mayo, de cohesión y calidad del Sistema Nacional de Salud", Boletín Oficial del Estado, no 128, 29-5-03.

- (2003): “Ley 16/2003, de 28 de mayo, de cohesión y calidad del Sistema Nacional de Salud”, Boletín Oficial del Estado, 꾸. 128, 29-5-03.

- (1995): “Real Decreto 63/1995, de 20 de enero, sobre ordenación de las prestaciones sanitarias del Sistema Nacional de Salud", Boletín Oficial del Estado, n우 35, 10-2-95.

- (1995): "Decreto Legislativo 1/1995, de 24 de marzo, por el que se aprueba el texto refundido de la Ley del Estatuto de los Trabajadores", Boletín Oficial del Estado, ํㅜ 75, 29-3-95.

- (1994): "Real Decreto Legislativo 1/1994, de 20 de junio, por el que se aprueba el texto refundido de la Ley General de la Seguridad Social”, Boletín Oficial del Estado, no 154, de 29 de junio de 1994.

- (1991): "Real Decreto 357/1991, de 15 de marzo, por el que se desarrolla, en materia de pensiones no contributivas, la Ley 26/1990, de 20 de diciembre, por la que se establecen en la Seguridad Social prestaciones no contributivas", Boletín Oficial del Estado, no 69, 21-3-91.

- (1991): "Real Decreto 356/1991, de 15 de marzo, por el que se desarrolla, en materia de prestaciones por hijo a cargo, la Ley $26 / 1990$, de 20 de diciembre, por la que se establecen en la Seguridad Social prestaciones no contributivas", Boletín Oficial del Estado, nํ6, 21-3-91.
- (1990): “Ley 26/1990, de 20 de diciembre, por la que se establecen en la Seguridad Social Prestaciones no contributivas", Boletín Oficial del Estado, nㅇ $306,22-12-90$.

- (1986): “Ley 14/1986, de 25 de abril, General de Sanidad”, Boletín Oficial del Estado, 꾼. 102 , 29-4-86.

- (1984): "Real Decreto 383/1984, de 1 de febrero, por el que se establece y regula el sistema especial de prestaciones sociales y económicas previsto en la Ley 13/1982, de 7 de abril, de integración social de los minusválidos", Boletín Oficial del Estado, n- 49, 27-2-84.

- (1982): “Ley 13/1982, de 7 de abril, de Integración Social de los Minusválidos", Boletín Oficial del Estado, no $103,30-4-82$.

- (1974): “Orden por la que se aprueba el Estatuto de Personal del Servicio Social de Asistencia a Pensionistas de la Seguridad Social”, Boletín Oficial del Estado, no 102, 29-4-74.

- (1971): "Orden por la que se regula el Plan Nacional de la Seguridad Social de Asistencia a los Ancianos", Boletín Oficial del Estado, ํㅜ 53, 3-3-71.

- (1971): “Orden por la que se dictan normas reglamentando los Convenios para la recaudación e ingreso de percepciones sobre productos regulados por Decreto 345/1971, de 25 de febrero", Boletín Oficial del Estado, no 269,10-11-1971.

- (1970): “Orden por la que se establece el Servicio Social de la Seguridad Social de asistencia a los ancianos", Boletín Oficial del Estado, $\mathrm{n} \times \mathbf{0} 70$, de 23-3-70.

FERNÁNDEZ ORRICO, F. J. (2008): “Prestaciones económicas para cuidados en el entorno familiar y Seguridad Social de cuidadores no profesionales", Revista del Ministerio de Trabajo y Asuntos Sociales, ํㅜ- 74, págs. 79-104.

GONZÁLEZ DE FRUTOS, P. (2006): “Hacia dónde va el Seguro español”, Información Comercial Española, no 833 , págs. 7-26.

GONZÁLEZ DE PATTO, R. M. (2011): La garantía jurisdiccional de las prestaciones de dependencia en el marco de la reforma del proceso social, Albacete, Bomarzo.

GONZÁLEZ ORTEGA, S. (2013): “Los datos generales del sistema para la autonomía y atención a la dependencia y su significado", en GONZÁLEZ ORTEGA, S. (dir.), La aplicación de la Ley de Dependencia en España, Madrid, CES, pág. 29-56.

- (2004): "La protección social de las situaciones de dependencia”, Relaciones Laborales, 는 20, págs. 17-18.

GUTIÉRREZ RESA, A. (2007): “Mayores y familia ante el futuro de los servicios sociales", Revista del Ministerio de Trabajo y Asuntos Sociales, $\mathrm{n}$ - 70 , págs. 81-105.

HERNÁNDEZ GONZÁLEZ, D. (2006): “El seguro privado dentro de la protección social de la dependencia: perspectivas y riesgos asociados" [tesis doctoral].

IMSERSO (2011): Libro blanco de la coordinación sociosanitaria en España, Madrid, Ministerio de Sanidad, Política Social e Igualdad. 
IMSERSO (2003): II Plan de Acción para las Personas con Discapacidad (2003-2007), Ministerio de Trabajo y Asuntos Sociales.

- (2003): Plan de Acción para las Personas Mayores 2003 2007, Ministerio de Trabajo y Asuntos Sociales.

- (2009): III Plan de Acción para las Personas con Discapacidad (2009-2012), Ministerio de Trabajo y Asuntos Sociales.

LA CASA GARCÍA, R.: “Prólogo", en MARTÍNEZ-GIJÓN MACHUCA, P. (2012): El seguro privado de dependencia, Madrid, Marcial Pons, pág. 10.

LÓPEZ CASASNOVAS; G.; y MOSTERÍN, A. (2008): “El gasto sanitario en el contexto del gasto social", Gaceta Sanitaria, ํㅡ 22, supl. 1, págs. 43-52.

MALDONADO MOLINA, J. A. (2011): “Las prestaciones por dependencia en el sistema español de protección social”, en SÁNCHEZ-RODAS NAVARRO, C. (dir.), Las prestaciones españolas por dependencia y el Derecho de la Unión, Murcia, Laborum, págs. 71-127.

- (2003): El seguro de dependencia. Presente y proyecciones de futuro, colección Laboral, Valencia, Tirant lo Blanch, págs. 49-56.

MARTín PINDADO, L. (2007): “La Ley de Promoción de la Autonomía Personal y de Atención a las Personas en Situación de Dependencia: las personas mayores", Revista del Ministerio de Trabajo y Asuntos Sociales, nㅜ 70, págs. 71-79.

MARTÍNEZ-GIJÓN MACHUCA, P. (2012): El seguro privado de dependencia, Madrid, Marcial Pons.

MOLERO MARAÑÓN, M. L. (2004): “Otras pensiones por vejez”, en BARRIOS BAUDOR, G. L. (coord.); y SEMPERE NAVARRO, A. V. (dir.), Pensiones por jubilación o vejez, Cizur Menor, Aranzadi, págs. 759-775.

MONEREO PÉREZ, J. L.; y FERNÁNDEZ BERNAT, J. A. (2008): “La protección social complementaria 'externa': el espacio privado en la protección de la dependencia”, en MONEREO PÉREZ, J. L. (dir.), Las contingencias comunes protegidas por la Seguridad Social. La Ley 40/2007, de 4 de diciembre de medidas en materia de Seguridad Social, Granada, Comares, pág. 737-760.

MONEREO PÉREZ, J. L. et al. (2010): Manual de Derecho de la dependencia, Madrid, Tecnos.

MONEREO PÉREZ, J. L. et al., (2007): La protección jurídica de las situaciones de dependencia. Estudio sistemático de la Ley 39/2006, de 14 de diciembre, de protección de la autonomía personal y atención a las personas en situación de dependencia, Granada, Comares.

PÉREZ ORTIZ, L. (2012): “Envejecimiento de la población y gastos sanitarios: más allá del determinismo demográfico", en BAZO, M. T. (coord.), Envejecimiento poblacional y el reto de la dependencia. El desafío del envejecimiento en los sistemas sanitarios y sociales de España y Europa, Nau Llibres, págs. 145-166.

PÉREZ YÁNEZ, R. M. (2007): “La protección social de la discapacidad generadora de dependencia”, en VV.AA., Situaciones de dependencia: situación actual y nuevas perspectivas, Thomson-Civitas.
ROA VENEGA, J. M.; y FERNÁNDEZ PRADOS, C. (2014): “Los cuidadores informales de personas mayores dependientes: aspectos psico-sociológicos", en VV.AA., GARCÍA GARNICA, M. C., cit., pág. 266.

RODRÍGUEZ CABRERO, G. (2007): "La protección social de la dependencia en España. Un modelo sui generis de desarrollo de los derechos sociales", Política y Sociedad, vol. 44, nํㅜ 2, págs. 69-85.

- (2004): "Referencias europeas de la protección social a la dependencia”, en CASADO PÉREZ, D. (dir.), Respuestas a la dependencia, Madrid, CCS, págs. 111-134.

- (1999): La protección social de la dependencia, Madrid, Imserso.

RODRÍGUEZ RODRÍGUEZ, P. (2006): El modelo de atención a la dependencia y los sistemas de protección social en España (SNS, servicios sociales y Seguridad Social), serie Documentos de Trabajo, nº 87/2006, Fundación Alternativas.

SANCHO CASTIELLO, M.; y DE LA PEZUELA PINTÓ, M. (2002): Datos básicos sobre servicios sociales para personas mayores en España. Enero 2001. Evolución de los indicadores de servicios, 19992001, Observatorio de Mayores, Imserso.

SEMPERE NAVARRO, A. V. (2008): "Presupuestos, antecedentes y gestación de la Ley", en SEMPERE NAVARRO, A. V. (dir.); y CHARRO BAENA, P. (coord.), Comentario sistemático a la Ley de la Dependencia. Ley 39/2006, de 14 de diciembre, de Promoción de la Autonomía Personal y Atención a las Personas en Situación de Dependencia y Normas Autonómicas, Cizur Menor, Thomson Aranzadi.

SOCIEDAD ESPAÑOLA DE GERIATRÍA Y GERONTOLOGÍA (2005): Análisis y evaluación de la red de servicios sanitarios dedicados a la dependencia: programas de prevención, atención domiciliaria y hospitalización.

SUÁREZ CORUJO, B. (2006): “Dependencia y Estado autonómico: el encaje competencial del proyecto de Ley de Protección de la Autonomía Personal y Atención a las Personas en Situación de Dependencia”, Relaciones Laborales, $\mathrm{n}$ 을, págs. 933-953.

TRIBUNAL DE JUSTICIA DE LA UNIÓN EUROPEA, SALA SEGUNDA (2011): "Sentencia de 30 de junio de 2011”, TJCE\2011\205.

VEIGA COPO A. B. (2008): El seguro de dependencia, Comares, Granada.

VIDA SORIA, J.; y GONZALO GONZÁLEZ, B. (2006-2007): "Sobre el futuro de las políticas de protección social: la promoción de la autonomía personal y la atención a la dependencia", Documentación Administrativa, nํ-276-277, págs. 113-124.

VIDA SORIA, J. et al., (2014): Manual de Seguridad Social, Madrid, Tecnos.

ZABARTE, M. E. (2006): “La dimensión múltiple de la atención a la dependencia: la conexión de los servicios sociales con la Seguridad Social y el Sistema Nacional de Salud", Revista del Ministerio de Trabajo y Asuntos Sociales, nํ 65, págs. 49-55. 